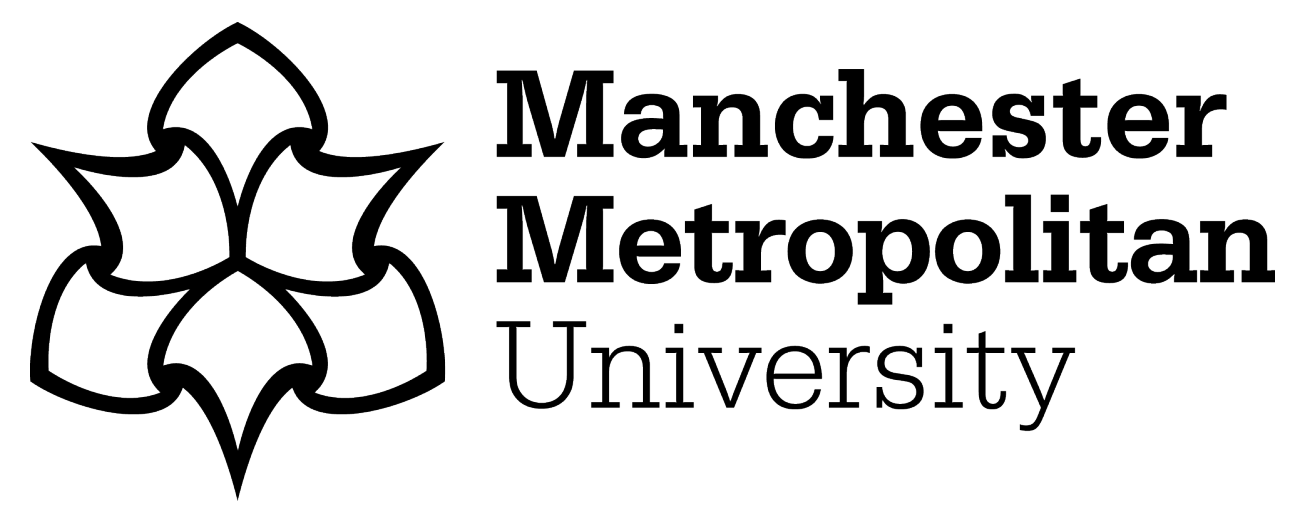

Wicker, Kate (2022) Credibility contests: the contributions of experiential knowledge to radicalisation expertise. Critical Social Policy, 42 (3). pp. 510530. ISSN 0261-0183

Downloaded from: https://e-space.mmu.ac.uk/628830/

Version: Published Version

Publisher: SAGE Publications

DOI: https://doi.org/10.1177/02610183211063609

Usage rights: Creative Commons: Attribution 4.0

Please cite the published version 


\title{
Credibility contests: The contributions of experiential knowledge to radicalisation expertise
}

\author{
K A T E W I C K E R \\ Education and Social Research Institute, Manchester Metropolitan \\ University, Manchester, England
}

\begin{abstract}
Radicalisation has become a highly influential idea in British policy making. It underpins and justifies Prevent, a core part of the UK's counterterrorism strategy. Experts have theorised the radicalisation process, often beset by a weak evidence base and mired in fundamental contestation on definitions and explanatory factors. Experiential experts have been active contributors to these debates, presenting a challenge to the low-ranking role often given to experiential knowledge in evidence hierarchies and a contrast to policy areas in which it remains poorly valued. This paper draws on interviews with radicalisation experts to examine the dynamics of this pluralisation in practice. With a focus on credibility contests, it explains how experiential experts can claim authoritative knowledge and the challenges they face from those who prioritise theory-driven empirical data as the basis for contributions to knowledge. The paper draws out the implications for understandings of expertise of this newly conceptualised, evidence poor and highly applied topic area.
\end{abstract}




\section{Key words \\ Evidence, ex-extremists, experts by experience, counter-terrorism, extremism, Prevent}

\section{Introduction}

Prevent has been in place for nearly twenty years and remains a key pillar of the UK's counter-terrorism strategy (HM Government, 2018). It seeks to stop people 'from becoming terrorists or supporting terrorism' (HM Government, 2018, 31). More specifically, it aims to prevent 'radicalisation' by countering and reducing support for extremist ideologies and intervening with individuals who are 'vulnerable' to supporting or committing terrorist acts. In this sense, Prevent is a risk management strategy that seeks to anticipate and pre-empt danger, part of a wider precautionary turn in countering terrorism (Martin, 2014). The wide net cast by this early intervention approach, and its impacts on individuals and communities, have been the subject of extensive debate and heavy criticism particularly since the introduction of the Prevent Duty in 2015 and its responsibilisation of public services in counter-radicalisation practice (e.g. Heath-Kelly and Strausz, 2019; Sabir, 2017).

The focus here is on radicalisation, the theory on which this policy arc stands. The UK government's understanding of radicalisation has been set out in successive Prevent policy documents. Concomitant to this policy development has been the emergence of a radicalisation expert community that has been active in researching and theorising the idea. A key segment of the expert community is experiential experts. Practitioners, ex-extremists and community activists have been visible from the start of the Prevent agenda, prominent in policy debates and active contributors to the development of radicalisation theory. This is in contrast to some areas of UK social policy in which relevant knowledge from experts by experience, for example drug users (Monaghan et al., 2018) and benefit claimants (Patrick, 2020), remains undervalued. Even in areas of policy making that have more recently sought participation, challenges remain in practice to the acceptance of non-established forms of expertise and the meaningfulness of their inclusion has been questioned (e.g. Smith-Merry, 2020; Tisdall, 2017).

Building on the debates over terrorism and expertise that have taken place in this journal (e.g. Glasby and Beresford, 2006; Ragazzi, 2017), the paper considers conceptualisations of radicalisation expertise with a particular focus on the role of experiential knowledge. It examines how the credibility of experiential experts is demonstrated as well as how it is challenged. These challenges have precedence within terrorism studies; terrorism experts 
have previously articulated concerns that unqualified or inexperienced individuals are able to claim seemingly authoritative insights on terrorism (e.g. Stampnitzky, 2011). Such debates raise questions about who is authorised to speak on radicalisation and the limitations on diversity in the expert community. A focus on contested expertise enables an analysis of how the boundaries of expertise are constructed on this topic to include or exclude different forms of knowledge.

The paper begins by providing background on evidence and expertise on radicalisation, as well the nature and role of experiential knowledge in conceptualisations of expertise. This is followed by an outline of the methods used in the research. Data is then presented on the ways by which the credibility of experiential experts is constructed and challenged on this topic.

\section{Knowledge on radicalisation and the boundaries of expertise}

Knowledge on radicalisation is embedded in the wider history of terrorism studies. Stampnitzky (2013, 49-82) traces a shift since the 1970s from policy and expert narratives of insurgency that acknowledged the relational dynamics of conflict situations to those of terrorism that depoliticised acts of political violence, instead characterising them as irrational and immoral. Since the early 2000s, the causes of terrorism in turn have been understood in terms of radicalisation and the focus of expert theory, policy and practice in this area has largely been on individual risk indicators and pathways (Silva, 2018; Younis, 2021). Research has shown that media reportage on terrorism tends to reflect dominant perspectives (Miller and Mills, 2009; Silva, 2018, 45-6), which constrains expert narratives and the sources that are able to speak on the topic (Ahmad, 2020). More generally, terrorism research has tended to work largely within the interests of the policy community (Mills et al., 2020). The boundaries of debate as well as the worthiness of different types of knowledge are actively constrained by such features of this policy-led and politicised topic area.

Underpinning policy narratives on radicalisation however are continuing weaknesses in the evidence base. The issues detailed by terrorism studies scholars, including a lack of empirical evidence, theoretical development and workable policy and practice recommendations (e.g. Sageman, 2014) have also been identified in radicalisation research (e.g. Bouhana and Wikstrom, 2011, 13-14; Feddes and Gallucci, 2015). While empirical evidence has cumulated on particular factors, there is a remaining lack of evidence around causality (Gøtzsche-Astrup, 2018). The conclusion of a parliamentary 
inquiry into radicalisation published shortly after the release of the current Prevent strategy was bleak: 'The weakness of the evidence base came across strongly during our inquiry' (Home Affairs Committee, 2012, 10). A particular issue is the exclusion of data on or from those processed by state interventions (Qureshi, 2020), with access blocked to researchers from the early days of Prevent (e.g. King and Taylor, 2011, 615-8). Although a recent review of terrorism studies finds an increase in methodological diversity and the use of primary data, it shows no sign of a rise in the use of direct accounts from such voices (Schuurman, 2020). The limited evidence base of Prevent has been a central refrain of the research and policy community from the start and undermines its central concept of radicalisation. Despite this, the concept has reshaped dominant understandings of the causes of terrorism, with implications seen in Prevent's broad application of risk parameters and continually disproportionate direction towards Muslim communities (Pettinger, 2020). The reach and impact of the concept despite its difficult evidence base raises questions as to the basis on which radicalisation expertise is claimed, attributed and assessed.

This then is a topic area led by a dominant policy narrative that lacks a strong evidence base. While these conditions have shaped the inclusivity and terms of expert debate, there remains diversity among the actors that contribute to knowledge generation and public debate on radicalisation. Research on the topic is multidisciplinary, and think tanks and official agencies are active sites of knowledge production alongside academia (Neumann and Kleinmann, 2013, 369-70). Mythen et al. (2017) argue that Prevent's narrow conceptualisation of radicalisation fails to reflect the diverse and often diverging research-based accounts coming from the expert community. While dominant understandings of radicalisation focus on individual risk, there are calls for more attention to political and social context (e.g. Schmid, 2013, 2-5). There is no clearly agreed-upon definition of 'radicalisation' (Bailey and Edwards, 2017), and the literature suggests that it is a complex, multifactorial process with a range of potential explanatory factors (e.g. McGilloway et al., 2015). Prevent itself is characterised by distributed governance and negotiated practice, with a myriad of activities and actors involved (Home Office, 2011, 95-106), subject to contestation over policy theory in the policy process and interpreted and implemented differently across local areas (O'Toole et al., 2016). This means that as national strategy filters through implementation structures, the meaning of radicalisation and the assessment of its associated risks is constructed in practice (Pettinger, 2020). Although UK counter-radicalisation policy and the dominant narrative that it promotes are myopic in their focus on the individual and the ideological, the expert community has produced conceptually and theoretically plural accounts and a range of specialist knowledge underpins the topic area. The paper analyses the construction of hierarchies of knowledge in this 
context, discussing the nature and implications of this broad and diverse distribution of knowledge in terms of expertise on radicalisation.

Radicalisation expertise is set in a context of broader changes in conceptualisations of the nature of expertise. Nowotny (2003) talks of the 'pluralisation of expertise' as the rise of experience as a source of authoritative knowledge alongside scientific knowledge and credentialed experts. There are ongoing efforts to recognise and utilise the potential contributions of experiential expertise in research, policy and practice (e.g. Stewart et al., 2020), and research has demonstrated cases where expert credibility has been extended to a wide range of actors (e.g. Epstein, 1995). As originally conceptualised, experiential knowledge is 'truth learned from personal experience with a phenomenon' (Borkman, 1976, 446), becoming expertise when paired with an ability to use that knowledge to address a problem (Borkman, 1976, 447). The significance of these discussions is that those who are attributed expertise have the power to make authoritative statements on the social world: they have a recognised ability to conceptualise and explain a particular issue, as in Gieryn's (1999) idea of epistemic authority. Any attribution of expertise is of course subject to the competition inherent to expert status (Evans, 2015, 21-3). Gieryn $(1999,1)$ says that "Credibility contests" are a chronic feature of the social scene: bearers of discrepant truths push their wares wrapped in assertions of objectivity, efficacy, precision, reliability, authenticity, predictability, sincerity, desirability, tradition'. The stakes are the believability of the knowledge claims and conceptual arguments that an expert is promoting, and the outcomes shape who can claim an authoritative voice on a topic.

Such contests are particularly apparent at the faultine between research and experience-based knowledge. Despite movements towards inclusive notions of expertise, the dominant discourse of evidence-based policy making remains focused on the primacy of knowledge from research and validity based on methodological rigour (SmithMerry, 2020). In terrorism studies, Jackson (2012) conceptualised 'unknown knowns' as knowledge that is ignored or downplayed, and may include that which is judged to be inferior or 'unscientific' by other analysts. Some have argued for more understanding of how counterterrorism strategies are experienced by those processed by counterterrorist systems and by Muslim communities more broadly (Jarvis, 2019; Qureshi, 2020). A different perspective comes from a terrorism scholar who states that many of those claiming expertise on terrorism post-9/11 'are not truly scholars, are not versed in the scientific method, and often pursue a political agenda' (Sageman, 2014, 566). Such comments signal attempts to reify the boundaries of expertise on the topic, and these debates on voice and representation indicate that the 
political and competitive nature of expertise is brought to the fore in this topic area.

\section{Methodology}

This paper draws on data from a pluralist analysis of radicalisation expertise that examined the diversity of the expert community's ideas, actors and knowledge types. From this pluralist framework came an inclusive conceptualisation of 'radicalisation expert' as those who claimed or were attributed expert knowledge, or whose research or experience was suggestive of a specialisation on the topic. The topic was defined as the nature and causes of radicalisation. This approach enabled a focus on where the boundaries of expertise are drawn by the wide set of actors who contribute to knowledge generation in practice. It complements other studies on core sets of terrorism researchers (e.g. Miller and Mills, 2009). The study focused on peer judgements, examining the competing claims to credible knowledge within the expert community.

The paper draws on data from interviews conducted with UK-based experts between October 2012 and October 2014. The research used techniques from the elite interviewing literature (Dexter, 2006; Wicker and Connelly, 2014). A semi-structured approach was taken, with the topic guide adapted as the research progressed and questioning responsive to interviewees' specialised knowledge. Thirty-two interviews were conducted, plus two pilot interviews. On the basis of a documentary analysis carried out as part of the wider project, a list of experts was created and purposively sampled. The sample included individuals with a range of substantive perspectives on radicalisation. It was comprised of fourteen academics, eleven think tank researchers, and seven working in policy, practice and communities. Many interviewees had diverse professional backgrounds across these sectors. Interviews were recorded, with transcription carried out by the author soon afterwards to enable ongoing reflection on the findings. Thematic accounts of initial interviews were produced to explore emergent themes and further refine interview schedules. Data was entered into NVivo and coded using both concepts from the research questions as well as ideas from the data itself (Mason, 1994, 91-95).

Ethical approval was gained from the University of Leeds. Privacy was a particular concern to interviewees, with eighteen requesting a copy of their transcript, four making revisions to their transcripts for the purposes of anonymisation or clarity of expression and thirteen requiring the approval of any quotations. Anonymity can be difficult with elite interviews (Walford, 1994, 89-90), with interviewees vulnerable as a result in terms of their relationships with colleagues (Blakeley, 2013, 165), and the risks of identification 
seem to have been recognised by those involved given the high proportion of checks and amendments requested.

A limitation of the research is its focus on only three types of experiential knowledge. This was reflective of the voices that were most visible in both public debate on the issue and in interview data and can also be attributed to pragmatic issues around access. A limitation of the current analysis is the age of the data; with Prevent entering British policy in 2003, the paper discusses expertise during the strategy's first eleven years. The issues raised by the paper however have broader implications for understandings of knowledge on radicalisation as well as expertise more generally.

\section{Defences and denials of the role of experiential knowledge in radicalisation expertise}

\section{The role of academic knowledge}

Academia is a particularly active site of knowledge generation on radicalisation, with one review finding that $71 \%$ of publications were in academic journals (Neumann and Kleinmann, 2013, 369). Certified, credentialised knowledge is often seen more broadly as constitutive of expertise (Shanteau et al., 2002), and Jackson $(2012,18)$ writes that 'social scientific credentials' are one way by which terrorism experts are 'authorised' to speak. Peer reviewed publications, qualifications and position were seen as important by some interviewees as ways to judge the expertise of themselves and others. For example, one said:

I' $m$ an academic and my expertise is measured by traditional metrics for academic expertise. It's actually very simple. I'm [a senior member of staff in $]$ a centre that studies radicalisation, I direct research projects in that area, I've published about it myself, so whatever traditional academic metric you use I would probably be considered an expert in that field. (25)

Conversely, interviewees that had not formally studied radicalisation were more hesitant to call themselves experts; a distinction was drawn between having knowledge on the subject and having a qualification and therefore expertise. Such comments echo Collins and Evans (2007)'s typology of knowledge and their contention that there is a real divide between ordinary peoples' expertise and specialists' expertise.

In the main however, academic metrics held limited authority among interviewees. Many discussed the limitations of research-based knowledge on this topic, describing it as disconnected and abstract, and arguing that 
the prioritisation of theory development had led to a lack of knowledge on the local dynamics of radicalisation. One researcher said:

Obviously if you' re coming in as an academic, for example if your $\mathrm{PhD}$ was on the thoughts of Osama bin Laden for example, you may know in depth AQ [al-Qaeda] ideology, but you're not necessarily aware of how that plays out locally in a British Muslim community or in a context like [English city] specifically. And also maybe the wider repercussions of those sorts of ideas. (11)

This emphasis on the local manifestations of radicalisation theory chimes with criticisms of radicalisation research for focusing on individual level analysis to the detriment of context. For some interviewees, the emphasis on the local was informed by an understanding of the topic as complex and applied: generalised knowledge on specialised topics was likely only to address an aspect of the issue, and unlikely to speak effectively to the practicalities of particular situations. Building a theoretical understanding of radicalisation discorded with responding to it as a practical problem; for those that prioritised the latter, academic knowledge had limited relevance and instead expertise was more credible if it was grounded in specific contexts. These comments came particularly from those engaged in research that was more closely connected to policy, practice and communities. They suggest a curtailing of the authority of academic knowledge within a context of a diverse expert community with significant non-academic audiences.

\section{The credibility of experiential experts}

In this context, experiential knowledge, including that from counterradicalisation practitioners, ex-extremists, and communities, has gained visibility. The 2011 House of Commons inquiry highlighted the potential of practitioner knowledge to contribute to radicalisation theory, particularly given the lack of 'objective data' available (Home Affairs Committee, 2012, 12), and both Home Affairs Committee inquiries on radicalisation have called witnesses from organisations engaged in practical counter-radicalisation work (Home Affairs Committee, 2012; Home Affairs Committee, 2016). There have also been a small number of vocal ex-extremists, with the Quilliam Foundation the clearest example, who use their personal experiences to offer generalised ideas about the nature of radicalisation. Hazel Blears, speaking as an opposition MP in a 2011 debate held shortly before the publication of the latest Prevent strategy, said that Quilliam 'have been enormously powerful and valuable in working out strategies to counter extremism' (Hansard, 2011: Column 10WH). The third group is community experts; at the time of the study, these were individuals from Muslim communities that were the main focus of counter-radicalisation work. An example of lay knowledge (Wynne, 
1996), this includes those who enter policy, practice and public debate through community activism. Such experts have been present in policy debates from the early days of Prevent, through for example the 2005 'Preventing Extremism Together' working groups (Home Office, 2005). These initiatives and comments give some validation to experiential expertise on radicalisation and all three types have been visible forms of expertise in public debates on the issue.

The credibility of experiential experts on this topic has multiple bases. Interviewees talked about practitioners' 'direct and personal experiences' (33) of radicalisation. Such comments spoke to the subjective nature of practitioners' knowledge, recently shown to be central to how Prevent assesses and responds to risk (Pettinger, 2020). The expertise of those who work on programmes like Channel, Prevent's risk management process, was noted because they are 'really really in constant contact with the really top end, cutting edge bit of radicalisation' (16). The credibility of these practitioners' expertise lay then in their observation of and interaction with particular cases of radicalisation, or knowledge of the dynamics of specific locations, based on privileged access to rare and covert activity over time. Given the gaps in primary data on this topic, practitioners' ability to gain such access is a source of credibility. Practitioners' knowledge was often described in terms of key policy issues, for example how ideologies spread and the role of 'ideologues'. Interviewees contrasted this detailed, proximal and applied knowledge with distal academic knowledge, here giving the example of the Strategy to Reach, Educate and Empower Teenagers violence prevention programme:

So for example you might have a local organisation like STREET that works in Brixton and nearby areas, where people know people who are being radicalised and they've been subject to those experiences themselves in the past and have resisted those influences. They would have a very specific in-depth awareness of the tactics and the procedures used by radicalisers that, you could not really buy that expertise from an academic that'd studied AQ or jihadist movements in the UK. (11)

In such comments, practitioners' knowledge on radicalisation is valued for its understanding of the practical, local dynamics of radicalisation, and on this basis they are seen as able to contribute authoritative statements on the nature of radicalisation.

Ex-extremists' knowledge on the other hand was described as first-hand, and its credibility lies particularly in its uniqueness. A think tank researcher talked about the expertise of "those people who have been through the process themselves and come out the other end' because 'they are some of the few people who actually have access to this thing we' re studying in the first 
place' (20). A researcher and former counter-terrorism practitioner discussed the basis of ex-extremists' expertise through comparison to academics':

they can give insights that as an academic working in university-shire, you won't speak enough Arabic, you won't have enough hours in the day to go out and talk to all the people that they can talk to, with the backgrounds that they can talk to. You won't be able to understand the context of the theological debates that go on online for example in extremist forums, you won't even be able to get access to them. (9)

Language skills and cultural knowledge are key credibility factors here and ex-extremists are seen to have a rare ability to shed light on a relatively inaccessible topic. Given the dominant interpretation of radicalisation as an individual process, the idea that ex-extremists are able to use their personal experience to report directly on it is particularly persuasive and underlines the role of experiential expertise in theorising radicalisation.

The 'insight' provided by ex-extremists is similar to understandings of community experts' credibility. Interviewees described expertise from communities as religious and cultural knowledge or a detailed understanding of contemporary dynamics within particular communities; a former government advisor on Prevent said that one source of radicalisation expertise is "experts in the community who know what the discourses are in the community and are able to say actually this discourse does impact quite heavily on radicalisation but that doesn't' (18). This expertise is based on long-term interaction with a community and its politics, often working against extremism, as well as, often, a shared personal identity. One interviewee for example identified the value of their contribution to radicalisation debates on the basis of 'academic research and also, and more importantly, a long community activism and engagement and understanding some of the critical political dynamics' (10). Credibility is drawn from a closeness to the communities in question; it comes from living and working in particular contexts and the resultant knowledge is described as rich, detailed and contextual. There are similarities here with other research in which community members have claimed a knowledge grounded in lived experience and characterised by an authenticity lacking in research-based knowledge (Thompson et al., 2012, 607-9). The authority of community knowledge on radicalisation was also supported by its policy relevance; it was knowledge of 'particular political or religious or other dynamics that are pertinent to this particular area at this moment in time' (10). For example, a Prevent officer in a local authority said that community expertise was 'not necessarily expertise in theory or concepts but expertise in the sense of 'why's this guy gone to Syria' (30). Similar to knowledge from practitioners and ex-extremists, community expertise was seen as essential to an understanding of contemporary radicalisation, and was distinguished from 
abstract, theoretical knowledge given its nature as embedded in specific contexts.

Overall then, experiential expertise is prominent in the policy and public debate on radicalisation and many in the expert community trust in its relevance and authority. Experiential experts can claim an ability to provide insights where research data is lacking, and a proximity to the policy problem in contrast to detached and generalizable knowledge. Credibility based on a close interaction with processes of radicalisation results in knowledge that supports the current policy focus on individual solutions. These characteristics echo understandings of experiential expertise that emphasise its pragmatic nature, prioritising problem solving over the accumulation of knowledge (Borkman, 1976, 449). While evidence hierarchies privilege big, scientific data (Smith-Merry, 2020), the distinctive character of radicalisation expertise is indicated by a strong theme of qualitative analysis and professional opinion. The valuing of experiential expertise for its closely detailed, specialised and rare knowledge points to the nature of radicalisation as topic area where a diversity of expertise exists.

\section{The contested role of experiential knowledge in radicalisation expertise}

It was clear from interviews however that those within the expert community challenge the credibility of all three types of experiential claim to expertise in multiple ways. The first challenge relates to the relevance of the knowledge offered. Some interviewees questioned the levels of specialist knowledge among counter-radicalisation practitioners, and highlighted the difficulty of verification because of limited research access. A think tank researcher for example was asked whether Prevent practitioners' direct work on counterradicalisation interventions would result in expert knowledge and responded that, 'A lot of them don't do any of that, a lot of them are sitting around not doing that at all, filling in fundraising forms for trying to get money in to do projects' (16). Such comments pointed to the variable levels of expertise of even specialised practitioners and the importance of the type of experience upon which experiential expertise is claimed. Similarly, some interviewees were sceptical about the extent to which ex-extremists' knowledge was based on involvement in violence. An academic said:

What struck me, obviously this is not to be generalised to all of them because I've only talked in-depth to one of them, is that this guy was never radicalised. This isn't what I call radicalisation, this is maybe teenage rebellion. Their claim to expertise, I wasn't impressed. (32) 
Here, non-criminal extremism is seen as almost irrelevant to radicalisation, a view that was widely held amongst interviewees. Although it is not surprising that the relevance of an individual's knowledge shapes their acceptance in an expert community, it appears here as a particularly powerful way by which the radicalisation expertise of practitioners and ex-extremists can be questioned.

Similar arguments were used to challenge the relevance of community experts' knowledge. An activist and researcher said that:

My own personal experiences of most Muslim community actors who were consulted with by Government did not have the time or resources or even the skills to actually do a thorough study of those people who might be deemed as radical. They might have engaged them in order to marginalise them in their own community institutions, but that wasn't the same thing as understanding the issues.

Here, relevant practical experience does not necessarily amount to expertise, and in particular is not equitable with research-based expert knowledge. Similarly, a former senior civil servant said that Muslim advisors 'did not live up to expectations on radicalisation [...] because I think it's broadly true that most Muslims don't know anything more about radicalisation and terrorism than do most other people' (29). Comments like this drew a line not only between 'most Muslims' and experts, but also between individuals who were recognised as experts in Muslim faith or communities, and experts on the specific topic of radicalisation. An ability to comment on relevant community dynamics and potential policy impacts was distinguished from an ability to contribute explanatory knowledge as a radicalisation expert.

The credibility of community experts' knowledge was also questioned through allusion to the idea of an 'Islamic experts industry'. The term denotes community groups maintained by government funding and thoroughly in line with Prevent's underlying ideology but without specialist knowledge or valid claims to representation, with echoes of the UK government's tendency to engage mainly with 'moderate' Muslims post-9/11 (e.g. Spalek and Imtoul, 2007). In terms of expertise, interviewees' comments focused on the space that Prevent funding created for claims of essential knowledge. A particularly clear exposition came from a think tank researcher:

Okay, the weird, what happened with Prevent, and this is all relevant, is that inevitably the Government puts up a load of money and then a load of credible experts come charging forwards saying 'yeah I'm an expert on this subject, I'm from the Muslim community, I'm a former nationalist skinhead', whatever, and it's like a money grab. And you've seen all these little experts pop up all over the place. (16) 
This describes a clear boundary around the expert community that excludes such self-identifying experts with limited relevant experience. Such comments also introduce the notion of bias, a powerful attack on credibility given the controversial nature of this policy area. This reflects a broader tendency in interviews to criticise other experts, both academic and experiential, for a lack of rigour due to ideological bias. Overall, the idea of an 'industry' points to self-serving experts and the role of politics, networks and funding in defining community expertise in policy processes. Thus, while policy relevance shapes the community expertise that is legitimated in policy processes, its ability to support attributions of expertise within the expert community is more convoluted.

Interviewees also used notions of analytical quality to question the credibility of experiential experts. Comments differentiated practitioners' experience from expertise on the basis of analytical frameworks; although practitioners may have made empirical observations, their convictions and the overriding practical imperative to their work limited the quality of knowledge generated. For example, one academic said:

I think that practitioners can do it. [...] The job of the scholar however is to go beyond that and to look at something in a much more systematic way. It's not the job of the youth worker to understand everything there is to know about radicalisation. They will understand a good deal about it because they're working with young people, young people talk to them and so on and they will form views about it, but they don't necessarily have the whole picture. (26)

Interviewees used the idea of scholarly analysis in such ways to indicate a boundary between expert knowledge and practitioner knowledge. The reference to not having 'the whole picture' also relates to a notion of particularity that was used to question the credibility of ex-extremists' expertise:

So we've got for example Against Violent Extremism, as a group, that brings together people who have had particular experiences in particular groups. And obviously they have real expertise within their particular group and at that particular moment in time. I think it's quite important that we focus on the timebound nature and the location-bound nature of a lot of that expertise. I think where a lot of the dangers come is when a particular set of experiences then become generalised, theorised into something which can be applied across wider periods of time and across wider geographical spaces and socio-cultural spaces. (28) 
Referring to a network of 'individuals who have dealt first-hand with extremism' (Institute for Strategic Dialogue, n.d.), this academic is applying limitations to the ability of specific individual experiences to be generalised into theories of radicalisation and used to claim expertise. Drawing attention to the partial nature of individual accounts is a strong critique given the majority understanding of radicalisation as a differentiated, complex process. In this sense, some individual accounts were able to contribute to an understanding of radicalisation and others to provide illustrative accounts of existing knowledge, but both could generally be differentiated from the original and explanatory insights constitutive of radicalisation expertise. The subjective nature of experiential accounts was also used to question expert credibility: interviewees differentiated the emotionally vested accounts of ex-extremists, which were seen to give a particular perspective of the issue based on ex-membership of a group, from the carefully analysed research data of experts. In this sense, while the subjective nature of experiential expertise lends credibility through its deep, specific and pragmatic knowledge, it is contested by those who value abstraction, and referring to objective knowledge is a powerful way of differentiating expertise from the controversial debate on this topic. Thus while the relevant and specialist knowledge of many experiential experts was recognised within the expert community, these facets of analytical quality were used to disqualify it from constituting radicalisation expertise.

Overall then, the credibility of experiential experts was contested along two main lines. First, their knowledge could be constructed as fundamentally limited, as marginally relevant to the key issue of violence, or as contextual but not specialised enough to be constitutive of radicalisation expertise. Second, the quality of experiential experts' contributions was limited through their nature as anecdotal, specific and subjective. Many such comments construct expertise as scholarly and research-based and thus exclude personal or professional experience. Given that academic research is itself criticised for not being grounded in local knowledge and practical realities, this indicates the flexible nature of radicalisation expertise. It suggests that being regarded as a 'radicalisation expert' is not necessary to make authoritative contributions to public debate, but that instead demonstrating expertise on a related topic is sufficient. This finding can also be linked to the varying ways by which different audiences make credibility judgements (Shapin, 1995, 268-271), particularly pertinent given the different domains within which radicalisation is analysed. Limited as the terms of discussion may be, the state as well as academia contribute to terrorism studies (Stampnitzky, 2011, 7), and the media facilitate extensive public discussion of radicalisation. This not only supports a diverse expert community but has also fostered extensive contestation and complex notions of credible expertise. Overall, the characterisation of the topic 
area as new and complex, the limitations to empirical research, and its policy driven nature interact to create a context that allows a diversity of claims to expertise to exist In turn, a diverse conceptualisation of expertise creates the conditions in which credibility is contested and authority falters.

\section{Conclusion}

The implications of this pluralist analysis of the radicalisation expert community are seen in the contested boundaries of its expertise. While experts seek to differentiate themselves from non-experts and from the wider public debate on this issue, they do it in diverse and often disputed ways. Although the data presented in this paper refer to radicalisation expertise during the first decade or so of Prevent, they carry broader meaning; radicalisation expertise presents a strong example of the rise in visibility and influence of experiential knowledge and a set of conditions that facilitate that success. Experiential experts on this topic can promote and defend their expertise by characterising it as rare and closely detailed local knowledge, a persuasive argument in the context of a developing topic area with no established group of experts or fixed notion of expertise. In the absence of a strong evidence base, referring to the challenges of data generation and the blind spots of academic research on this topic creates space for alternative ways of demonstrating relevant and useful knowledge. Official statements, particularly towards the beginning of the Prevent agenda, bolstered these arguments through their articulations of limited knowledge on the topic and desire to hear from those regarded as having direct knowledge of the issues. More generally, experiential expertise draws on an account of expert credibility that speaks less to generating theory-driven empirical knowledge and more to policy relevance. The ability to understand and explain real scenarios and make recommendations for practice is valued by those that address applied questions. This might be expected given that the concept of radicalisation originated in policy, official funding has supported the work of the expert community, and counter-radicalisation remains a core part of the UK's counter-terrorism approach; knowledge from outside the academic community has thrived given the highly applied nature of this topic.

It is useful to consider the transferability of this research and the implications that can be drawn as to the nature of expertise and its mobilisation in policy making processes. We might expect that a similarly controversial and much-discussed topic area like UK drugs policy would also feature vocal experiential experts. However, while the drugs debate is closed to alternative voices, particularly drug users, by historically dominant policy framings and expert communities (Monaghan et al., 2018), the diversity in 
radicalisation debates is fostered by the nature of the topic area as newly conceptualised with sparse and contested evidence. Conversely, while there are longstanding strategic efforts to use experiential expertise in healthcare policy making, in practice it remains marginalised here too (O'Shea et al., 2019). In particular, scientific expertise remains dominant and experiential expertise must usually be supported by another form of evidence in order to gain credibility (Mazanderani et al., 2020). The case of radicalisation again provides a contrast to this; as a topic that draws in a broad spectrum of specialisms, competing notions of authoritative knowledge mean that authority is less tied to science and sources of credibility are more variable. Experiential expertise was frequently justified through reference to subjective experience rather than research knowledge and in this sense experiential experts are a distinct part of the expert community drawing on alternative notions of credibility. Similarly, while science is the ultimate marker of authority in Gieryn's (1999) conceptualisation of credibility contests, not all radicalisation experts attempt to justify their contributions in terms of science. Building on understandings of terrorism expertise as non-institutionalised (Stampnitzky, 2013), the sub-topic of radicalisation demonstrates the relevance and contribution of different forms of knowledge and the flexible and permeable boundaries of the expert community. The characteristics of radicalisation expertise suggest then the potential of a newly conceptualised, evidence poor and highly applied topic to create an opening in science-dominant conceptualisations of expertise.

Overall then, experiential knowledge is a powerful marker of authority on this topic, supporting articulations of the boundaries of expertise and enabling participation in policy and public debate. Examining the diversity and contestation underpinning the dominant ideas of radicalisation behind Prevent indicates that part of the power of the radicalisation narrative is drawn from the myriad ways that authority can be claimed on it. At the same time, the data shows other experts challenging the credibility of experiential knowledge on radicalisation by reference to its relevance and subjective nature. Flexible notions of authoritative knowledge enable experiential expertise to be resisted by those that conceptualise credibility in terms of theory-driven empirical investigations and value methodological integrity and theoretical advancement. While the boundaries of expertise may have been extended in some ways to enable a diverse set of experts to participate in generating understandings of radicalisation, clearly the stakes of epistemic authority are high and academic expertise will attempt to defend itself.

The data also speak then to broader discussions on the structures that permit or mute voice on this topic. Experiential experts have attempted to contribute knowledge to understandings of radicalisation, and have gained some success in policy and public debate, yet there is resistance from parts of the research community. On such a highly contested topic, this raises issues of inclusivity in conceptualisations of both expertise and radicalisation. There 
have been recent calls to listen widely to different forms of knowledge on terrorism as a way of expanding the parameters of debate (e.g. Jarvis, 2019; Qureshi, 2020). As demonstrated by the credibility contests (Gieryn, 1999) discussed in this paper however, reports of lived experience face active attempts at exclusion from understandings of expertise. Moreover, dominant framings of the policy problem limit who can speak from an experiential position, as indicated by the absence of those processed by counter-terrorism strategies like Prevent in policy making and research. These constraints on diversity in the expert community, alongside the fundamentally contested boundaries of expertise on this topic that mean that there is no one clear, exclusionary notion of authority, reinforce the value of inclusive debates that expand the types of knowledge that are listened to. Finally, while the paper has focused specifically on the struggles of experiential knowledge, and while collaborative approaches to research increasingly attempt to recognise and value such knowledge, the power dynamics within universities themselves and the exclusion of Black, Asian and minority ethnic researchers within academic practice are being increasingly scrutinised (Brown et al., 2020). These issues of power define the experiences that are worth knowing and in turn shape understandings of the topic. The outcomes of credibility contests and the relative epistemic authority of experts is particularly pertinent in this policy relevant topic area that has wide-ranging impacts on the communities and individuals that are judged to fall within its remit. An understanding of the complex ways by which expertise is actively constructed, defended and denied helps to explain the authority not only of particular experts but the continuation and direction of Prevent as a highly controversial strategy.

\section{Acknowledgements}

The author would like to thank Mark Monaghan, Deborah James and Kate Pahl, as well as the editorial collective and anonymous reviewers from Critical Social Policy, for their thoughtful comments on earlier versions of this paper.

\section{Declaration of conflicting interests}

The authors declared no potential conflicts of interest with respect to the research, authorship, and/or publication of this article.

\section{Funding}

The authors disclosed receipt of the following financial support for the research, authorship, and/or publication of this article: This work was supported by the Economic and Social Research Council (grant number ES/ J500215/1). 


\section{References}

Ahmad J (2020) Constructing the islamic state: Analysing the interplay between media and policy frames in the aftermath of the November 13th 2015 Paris attacks. Critical Studies on Terrorism 13(4): 568-590.

Bailey G and Edwards P (2017) Rethinking 'radicalisation': Microradicalisations and reciprocal radicalisation as an intertwined process. Journal for Deradicalization 10: $255-281$.

Blakeley R (2013) Elite interviews. In: Shepherd LJ (eds) Critical Approaches to Security. Abingdon, Oxon: Routledge, 158-168.

Borkman T (1976) Experiential knowledge: A New concept for the analysis of selfhelp groups. Social Service Review 50(3): 445-456.

Bouhana N and Wikstrom P-OH (2011) Al Qa'ida-Influenced Radicalisation: A Rapid Evidence Assessment Guided by Situational Action Theory. London: Home Office. Available at: https://www.gov.uk/government/publications/al-qaida-influencedradicalisation-a-rapid-evidence-assessment (accessed 9 November 2021).

Brown M, Pahl K, Rasool Z, et al. (2020) Co-producing research with communities: Emotions in community research. Global Discourse 10(1): 93-114.

Collins H and Evans R (2007) Rethinking Expertise. Chicago: University Of Chicago Press. Dexter LA (2006) Elite and Specialised Interviewing. Colchester: ECPR Press.

Epstein S (1995) The construction of Lay expertise: AIDS activism and the forging of credibility in the reform of clinical trials. Science, Technology, \& Human Values 20(4): 408-437.

Evans R (2015) What is expertise? Technical knowledge and political judgement. In: Berling T V and Bueger C (eds) Security Expertise: Practice, Power, Responsibility. Abingdon, Oxon: Routledge, 19-36.

Feddes AR and Gallucci M (2015) A literature review on methodology used in evaluating effects of preventive and De-radicalisation interventions. Journal for Deradicalization 15/16(5): 1-27.

Gieryn TF (1999) Cultural Boundaries of Science: Credibility on the Line. Chicago: University of Chicago Press.

Glasby J and Beresford P (2006) Commentary and issues: Who knows best? Evidence-based practice and the service user contribution. Critical Social Policy 26(1): 268-284.

Gøtzsche-Astrup O (2018) The time for causal designs: Review and evaluation of empirical support for mechanisms of political radicalisation. Aggression and Violent Behaviour 39: 90-99.

Hansard (2011) Quilliam Foundation. Tuesday 15 March, Volume 525. Available at: https:/hansard.parliament.uk/Commons/2011-03-15/debates/11031559000001/ QuilliamFoundation (accessed 9 November 2021).

Heath-Kelly C and Strausz E (2019) The banality of counterterrorism "after, after 9/ 11 "? perspectives on the prevent duty from the UK health care sector. Critical Studies on Terrorism 12(1): 89-109. 
HM Government (2018) CONTEST: The United Kingdom's Strategy for Countering Terrorism, Cm 9608. Available at https://assets.publishing.service.gov.uk/gove rnment/uploads/system/uploads/attachment_data/file/716907/140618_CCS207 _CCS0218929798-1_CONTEST_3.0_WEB.pdf (accessed 9 November 2021).

Home Affairs Committee (2012) Roots of violent radicalisation, HC 1446. Available at https://www.publications.parliament.uk/pa/cm201012/cmselect/cmhaff/1446/ 1446.pdf (accessed 9 November 2021).

Home Affairs Committee (2016) Radicalisation: the counter-narrative and identifying the tipping point. Available at: https://publications.parliament.uk/pa/cm201617/ cmselect/cmhaff/135/135.pdf (accessed 9 November 2021).

Home Office (2005) 'Preventing Extremism Together' Working Groups, August-October 2005. Available at: http://wnc.equalities.gov.uk/publications/doc_details/240preventing-extremism-2005-home-office-report.html (accessed 14 January 2017).

Home Office (2011) Prevent Strategy. Available at: http://www.homeoffice.gov.uk/ publications/counter-terrorism/prevent/prevent-strategy/ (accessed 9 November 2021).

Institute for Strategic Dialogue (n.d.) Against Violent Extremism (AVE) network. Available at: https://www.isdglobal.org/against-violent-extremism-ave (accessed 9 November 2021).

Jackson R (2012) Unknown knowns: The subjugated knowledge of terrorism studies. Critical Studies on Terrorism 5(1): 11-29.

Jarvis L (2019) Terrorism, counter-terrorism, and critique: Opportunities, examples, and implications. Critical Studies on Terrorism 12(2): 339-358.

King M and Taylor DM (2011) The radicalization of homegrown jihadists: A review of theoretical models and social psychological evidence. Terrorism and Political Violence 23(4): 602-622.

Martin T (2014) Governing an unknowable future: The politics of Britain's Prevent policy. Critical Studies on Terrorism 7(1): 62-78.

Mason J (1994) Linking qualitative and quantitative data analysis. In: Bryman A and Burgess RG (eds) Analysing Qualitative Data. London: Routledge, 89-110.

Mazanderani F, Noorani T, Dudhwala F, et al. (2020) Knowledge, evidence, expertise? The epistemics of experience in contemporary healthcare. Evidence $\mathcal{E}$ Policy 16(2): 267-284.

McGilloway A, Ghosh P and Bhui K (2015) A systematic review of pathways to and processes associated with radicalization and extremism amongst muslims in western societies. International Review of Psychiatry 27(1): 39-50.

Miller D and Mills T (2009) The terror experts and the mainstream media: The expert nexus and its dominance in the news media. Critical Studies on Terrorism 2(3): 414-437.

Mills T, Massoumi N and Miller D (2020) The ethics of researching 'terrorism' and political violence: A sociological approach. Contemporary Social Science 15(2): $119-133$. 
Monaghan M, Wincup E and Wicker K (2018) Experts, expertise and drug policymaking. Howard Journal of Crime and Justice 57(3): 422-441.

Mythen G, Walklate S and Peatfield E-J (2017) Assembling and deconstructing radicalisation in PREVENT: A case of policy-based evidence making? Critical Social Policy 37(2): 180-201.

Neumann P and Kleinmann S (2013) How rigorous Is radicalization research? Democracy and Security 9(4): 360-382.

Nowotny H (2003) Democratising expertise and socially robust knowledge. Science and Public Policy 30(3): 151-156.

O'Shea A, Boaz AL, et al. (2019) A hierarchy of power: The place of patient and public involvement in healthcare service development. Front Sociol 4: 38.

O'Toole T, Meer N, DeHanas DN, et al. (2016) Governing through prevent? Regulation and contested practice in state-muslim engagement. Sociology 50(1): 160-177.

Patrick R (2020) Unsettling the anti-welfare commonsense: The potential in participatory research with people living in poverty. Journal of Social Policy 49(2): 251270 .

Pettinger T (2020) British Terrorism preemption: Subjectivity and disjuncture in channel "de-radicalization" interventions. British Journal of Sociology 71(5): 970-984.

Qureshi A (2020) Experiencing the war "of" terror: A call to the critical terrorism studies community. Critical Studies on Terrorism 13(3): 485-499.

Ragazzi F (2017) Countering terrorism and radicalisation: Securitising social policy? [themed section]. Critical Social Policy 37(2): 163-267.

Sabir R (2017) Blurred lines and false dichotomies: Integrating counterinsurgency into the UK's Domestic 'war on terror.'. Critical Social Policy 37(2): 202-224.

Sageman M (2014) The stagnation in terrorism research. Terrorism and Political Violence 26(4): 565-580.

Schmid AP (2013) Radicalisation, De-Radicalisation, Counter-Radicalisation: A Conceptual Discussion and Literature Review. Available at: http://www.icct.nl/ download/file/ICCT-Schmid-Radicalisation-De-Radicalisation-CounterRadicalisation-March-2013.pdf (accessed 9 November 2021).

Schuurman B (2020) Research on terrorism, 2007-2016: A review of data, methods, and authorship. Terrorism and Political Violence 32(5): 1011-1026.

Shanteau J, Weiss DJ, Thomas RP, et al. (2002) Performance-based assessment of expertise: How to decide if someone is an expert or not. European Journal of Operational Research 136(2): 253-263.

Shapin S (1995) Cordelia's love: Credibility and the social studies of science. Perspectives on Science 3(3): 255-275.

Silva DMD (2018) 'Radicalisation: The journey of a concept', revisited. Race $\mathcal{E}$ Class 59(4): 34-53.

Smith-Merry J (2020) Evidence-based policy, knowledge from experience and validity. Evidence \& Policy 16(2): 305-316. 
Spalek B and Imtoul A (2007) Muslim communities and counter-terror responses: "hard" approaches to community engagement in the UK and Australia. Journal of Muslim Minority Affairs 27(2): 185-202.

Stampnitzky L (2011) Disciplining an unruly field: Terrorism experts and theories of scientific/intellectual production. Qualitative Sociology 34(1): 1-19.

Stampnitzky L (2013) Disciplining Terror: How Experts Invented "Terrorism". Cambridge: Cambridge University Press.

Stewart E, Smith-Merry J, Geddes M, et al. (2020) Opening up evidence-based policy: Exploring citizen and service user expertise. Evidence E Policy 16(2): 199-208.

Thompson J, Bissell P, Cooper C, et al. (2012) Credibility and the 'professionalized' lay expert: Reflections on the dilemmas and opportunities of public involvement in health research. Health 16(6): 602-618.

Tisdall EKM (2017) Conceptualising children and young people's Participation: Examining vulnerability, social accountability and co-production. The International Journal of Human Rights 21(1): 59-75.

Walford G (1994) Reflections on researching the powerful. In: Walford G (eds) Researching the Powerful in Education. London: UCL Press, 222-231.

Wicker K and Connelly L (2014) The practice of elite interviewing in politicised policy areas. In SAGE Research Methods Cases: https://www.doi.org/10.4135/ 978144627305013509940.

Wynne B (1996) May the sheep safely graze? A reflexive view of the expert-Lay knowledge divide. In: Lash S, Szerszynski B and Wynne B (eds) Risk, Environment and Modernity. London: Sage, 44-83.

Younis T (2021) The psychologisation of counter-extremism: Unpacking PREVENT. Race E Class 62(3): 37-60.

\section{Author biography}

Kate Wicker is a Research Assistant in the Education and Social Research Institute at Manchester Metropolitan University where she works on applied educational research projects. She holds a PhD in Sociology and Social Policy and a Masters in Social Research from the University of Leeds. 